\title{
Identifying Gender Disparities and Barriers to Measuring the Status of Female Faculty: The Experience of a Large School of Medicine
}

\author{
Irene C. Kuo, MD, Rachel B. Levine, MD, MPH, Estelle B. Gauda, MD, Joann Bodurtha, MD, MPH, \\ Janice Clements, PhD, Barbara Fivush, MD, and Lisa Ishii, MD, MHS
}

\begin{abstract}
Background: Women in academic medicine are not attaining parity with men in several domains. This issue is not only one of fairness; some funding agencies are requesting data on gender benchmarking. However, most published reports on gender disparities have not included examination of trends or actionable recommendations to address them.

Materials and Methods: The Dean of the Johns Hopkins University School of Medicine charged the Committee on the Status of Women (CSW) with conducting a comprehensive review of gender equity. In 2014, the CSW identified key domains important for academic success and created a sustainable framework to monitor trends by gender. Utilizing data from multiple key sources, the CSW measured differences in the domains of academic promotion, leadership, and satisfaction.

Results: Gender differences were present in each domain. Data were not centralized and not readily available for most domains. The CSW recommended strategies to address gender disparities and created a set of measurable recommendations to monitor progress. The recommendations include requiring detailed descriptions of departmental organizational leadership charts; diverse compositions of both search committees and applicant pools; increased proportion of female faculty in top-tier leadership positions; and transparent departmental promotions criteria and processes.

Conclusions: To maintain progress, we recommend that data be readily and easily accessible from a central institutional registry rather than come from multiple sources, that data be analyzed on a regular basis, and that results be shared across the institution to ensure transparency and accountability.
\end{abstract}

Keywords: academic medicine, gender inequity, leadership, faculty satisfaction, promotion, women's status, gender disparity

\section{Introduction}

D ESPITE A STEADY increase in the number of women faculty in the United States medical schools, they remain underrepresented in top leadership positions and at senior ranks. In 2015, women comprised $16 \%$ (20/125) of permanent deans of the United States medical schools and $16 \%(437 / 2768)$ of department chairs. ${ }^{1}$ A review of leadership positions in our Department of Medicine demonstrates gender disparity consistent with national findings. ${ }^{2}$

It is imperative that academic institutions develop greater accountability in addressing gender disparity. Some funding agencies are now requiring demonstration of gender equality. A pilot program of The New York Stem Cell Foundation requires grant applicants to submit a "gender report card" to “evaluate institutions' commitment to promoting gender equality ... and to encourage institutions to promote gender equality in science, medicine and engineering and to create programs to make it possible." 3 The report card requests gender composition of students, faculty at each rank, invited speakers, and of promotion and finance committees. Some accrediting agencies such as the Liaison Committee on Medical Education (which accredits medical education programs) and the American Psychological Association Committee on Accreditation are likewise requesting policies and practices that ensure diversity with regard to characteristics, such as age, ethnicity, and gender. ${ }^{4}$

Diversity and equity are important to institutional success. We report a process for measuring the status of women faculty in three key domains utilizing data from multiple

Department of Ophthalmology, Wilmer Eye Institute, Johns Hopkins University School of Medicine, Baltimore, Maryland. 
institutional sources. Our purpose was twofold: (1) to examine data and practices from our institution that could underlie and propagate gender disparities and (2) to establish specific goals and recommendations to address disparity.

\section{Materials and Methods}

The Johns Hopkins University School of Medicine (JHUSOM) Committee on the Status of Women (CSW) is a standing volunteer committee sanctioned by the Dean and charged with monitoring the status of women faculty and making recommendations to address barriers leading to gender disparity; the Associate Dean for Women (B.F.) chairs this committee. All CSW members are Associate or Full Professors; all departments are encouraged to send a representative. Between January and August 2014, committee members comprising faculty from $13 \mathrm{JHUSOM}$ departments met regularly to consider how to assess the status of women faculty. In 2009, a precursor to the CSW noted persistent inequity by gender, despite recommendations from a 2005 committee to combat faculty inequities by gender and barriers to academic progression. Based on data from these two committees, the CSW identified three critical domains: (1) promotion, (2) leadership, and (3) faculty satisfaction. A subcommittee consisting of three to five members collected and reviewed data for each domain. The report was completed in October 2014.

\section{Promotion}

The faculty promotions subcommittee gathered data to compare female and male full-time faculty members. The JHUSOM uses two promotions committees (Associate and Full Professor) and has a single-track promotions model. All faculty members are on the same track; tenure (or "contract to retirement") is granted only upon attaining the rank of Full Professor. Recent promotions data 2011-2013 and data from cohorts from the late 1990s to 2013 were available. The subcommittee examined (1) time to promotion from Assistant to Associate and from Associate to Full Professor, (2) number of publications and grants for promotion from Assistant to Associate Professor, and (3) proportion by gender of candidates promoted.

\section{Leadership}

The leadership subcommittee reviewed formal leadership appointment structures and leadership positions. Gender parity was assessed in the following leadership positions: Dean, Vice Deans, Associate Deans, Assistant Deans, and Department Directors (i.e., department chairpersons). In addition, the subcommittee examined the gender and rank of faculty in each of the 31 departments at the JHUSOM. The subcommittee also analyzed the composition of JHUSOM search committees over the last two decades. Last, it approached the Dean's office and the Registrar's office for data regarding leadership structure in individual departments.

\section{Satisfaction}

The JHUSOM considers faculty satisfaction a critical metric of institutional success. Satisfaction with position and institution correlate with a more stable workforce., ${ }^{5,6}$ Previous JHUSOM Faculty Satisfaction Surveys, conducted every 2 years, indicated that female faculty had less overall job satisfaction, a more negative perception of advancement, and less satisfaction with work-life balance than did male faculty. Additionally, voluntary exit surveys and interviews conducted over the prior decade of departing JHUSOM faculty indicated that job satisfaction was the main factor influencing their decision to leave the JHUSOM.

In 2013, the CSW along with the Office of Faculty Development administered a Satisfaction Survey to all the JHUSOM faculty adapted from the University of WisconsinMadison Study of Faculty Worklife. ${ }^{7}$

We used descriptive statistics to summarize data from all sources. We utilized $t$-tests and calculated 95 th percentile confidence intervals where appropriate to compare responses by gender.

\section{Results}

\section{Promotion}

The proportion of women faculty (37\% in 2014) in the JHUSOM has increased over the past decade in both clinical and basic science departments. In the clinical departments, in 2014, 20\% of Professors were women; in the basic science departments, the proportion was $23 \%$. With regard to grouping of female faculty in clinical departments by rank, in 2014, 99 (12\%) of all 811 female faculty members were Full Professors and 534 (66\%) were Assistant Professors or instructors (Table 1). In 2014, 390 (29\%) of 1330 male faculty members were Full Professors and 594 (44\%) were Assistant Professors or instructors.

In terms of gender breakdown per rank, in 2014, female clinical faculty comprised 99 (20\%) of 489 Full Professors, 178 (34\%) of 524 Associate Professors, and slightly less than half of all Assistant Professors (47\%) and instructors (49\%). Table 2 shows the breakdown of basic science faculty members.

From 2011 to 2013, the length of time to promotion to Associate Professor for women was longer than for men.

Table 1. Percentage of Rank by Gender in Clinical Departments AT THE JOHNS Hopkins UNIVERSITY SCHOOL OF MEDICINE

\begin{tabular}{llccc}
\hline & \multicolumn{1}{c}{ Professor } & Associate Professor & Assistant Professor & Instructor \\
\hline $\begin{array}{l}\text { Proportion within each rank who } \\
\text { are female }\end{array}$ & $20 \%(99 / 489)$ & $34 \%(178 / 524)$ & $47 \%(442 / 940)$ & $49 \%(92 / 188)$ \\
$\begin{array}{l}\text { Proportion holding each rank among } \\
\quad \text { all female faculty }\end{array}$ & $12 \%(99 / 811)$ & $22 \%(178 / 811)$ & $55 \%(442 / 811)$ & $11 \%(92 / 811)$ \\
$\begin{array}{l}\text { Proportion holding each rank among } \\
\text { all male faculty }\end{array}$ & $29 \%(390 / 1330)$ & $26 \%(346 / 1330)$ & $37 \%(498 / 1330)$ & $7 \%(96 / 1330)$ \\
\hline
\end{tabular}


Table 2. Percentage of Rank by Gender in Basic Science Departments at the Johns Hopkins University School of Medicine

\begin{tabular}{llccc}
\hline & Professor & Associate Professor & Assistant Professor & Instructor \\
\hline $\begin{array}{l}\text { Proportion within each rank who are female } \\
\begin{array}{l}\text { Proportion holding each rank among } \\
\text { all female faculty }\end{array}\end{array}$ & $38 \%(17 / 74)$ & $38 \%(11 / 29)$ & $30 \%(13 / 44)$ & $100 \%(4 / 4)$ \\
$\begin{array}{l}\text { Proportion holding each rank among } \\
\text { all male faculty }\end{array}$ & $54 \%(57 / 106)$ & $17 \%(18 / 106)$ & $29 \%(31 / 106)$ & $0(0 / 106)$ \\
\hline
\end{tabular}

Female MDs who were successfully promoted to Associate Professor had fewer overall publications and first and last author publications compared with female $\mathrm{PhD}$, male MDs, and male PhDs (Fig. 1); they also had the longest time to promotion to Associate Professor, taking 12-30 months longer than female $\mathrm{PhD}$, male MDs, and male $\mathrm{PhDs}$ (Fig. 2).

From examination of decade-long cohorts, the number of Associate Professor men presenting to the JHUSOM Professorial Promotion Committee (PPC) was two to three times the number of Associate Professor women put up for promotion, although this was not the ratio of total number of male Associate Professors to female Associate Professors. However, there was no difference in the proportion of candidates, male or female, successfully promoted to Full Professor once they had reached the JHUSOM promotions committee. The proportion of faculty members promoted to Professor who are female has remained constant at $\sim 25 \%-30 \%$. Promotion to Professor took 18 months longer for women than men who entered as Associate Professors. There were no data on number of publications by gender.

Individual departments decide when to put faculty up for promotion. It was noted that promotion processes and standards vary at the departmental level.

\section{Leadership}

The majority of leadership positions in the JHUSOM at the time of our committee's report (2014) were held by men. Women comprised $41 \%$ of Dean positions (17/41) and $6 \%$ of Department Director positions (2/31). Women held a large proportion (48\% or $16 / 33)$ of Assistant (8/13) and Associate Deanships (8/20). Female faculty held slightly more than half (9/16) of these positions; nonfaculty women held the remainder $(7 / 16 ;$ e.g., Associate Dean of Diversity or Associate Dean for Faculty Development). Of the eight executive and Vice Dean positions, only one (Vice Dean of Faculty) was filled by a woman, who also was a Department Director (J.C.). In 2014, of our 31 departments, there were two female Department Directors - one in basic science and one in a clinical department. The proportion of women (both faculty and nonfaculty) on 35 Department Director search committees since 1999 has ranged from $0 \%$ to $50 \%$ with a median of $26 \%$; only three such committees had a female chair or co-chair.

Information on the gender and rank of faculty members in each department was not registered centrally and had to be requested from each department. Organizational leadership charts of departments also were not readily available from a

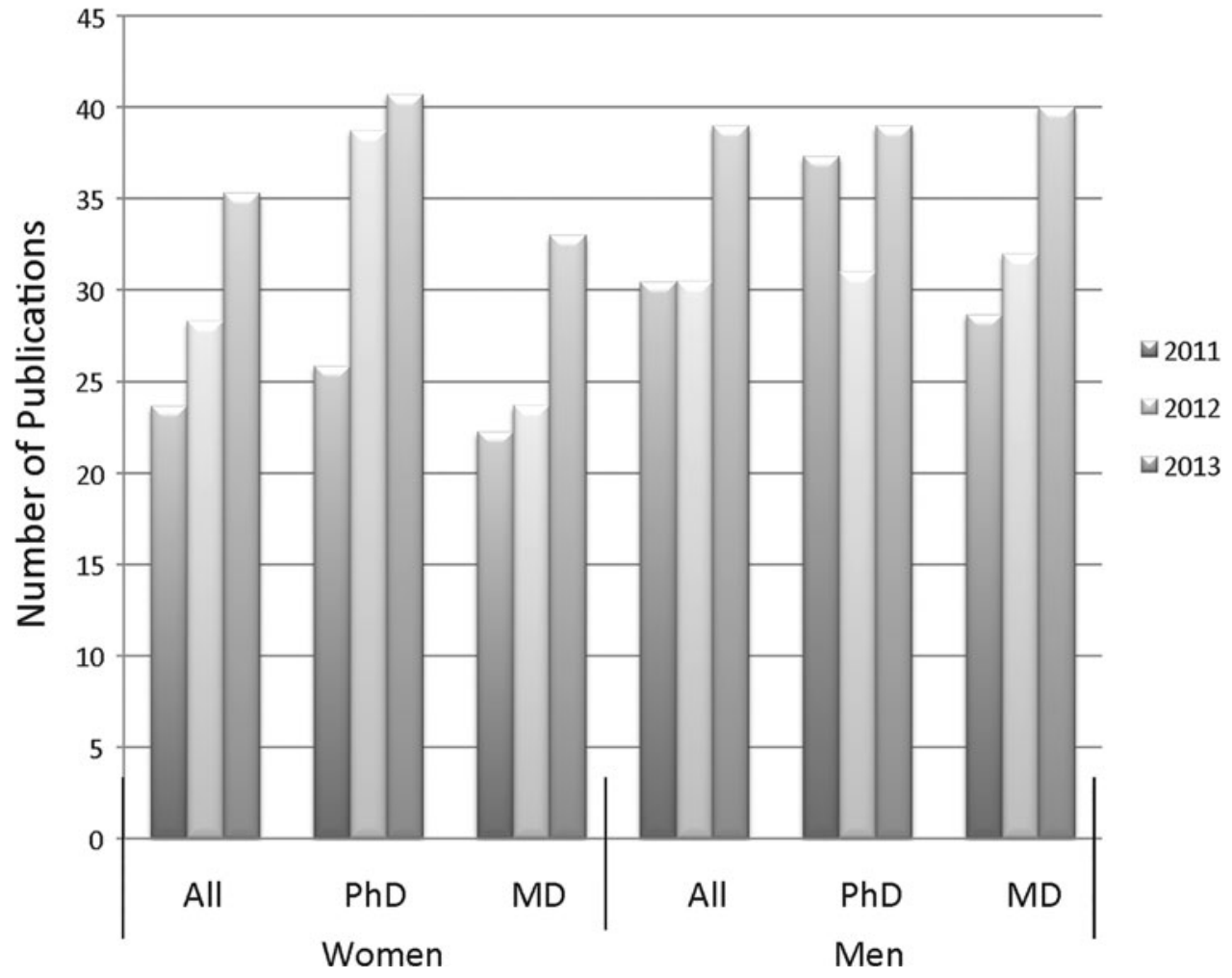

FIG. 1. Mean number of publications for male and female candidates successfully promoted from Assistant to Associate Professor between 2011 and 2013 . 
FIG. 2. Mean length of time for promotion for male and female candidates successfully promoted from Assistant to Associate Professor between 2011 and 2013.

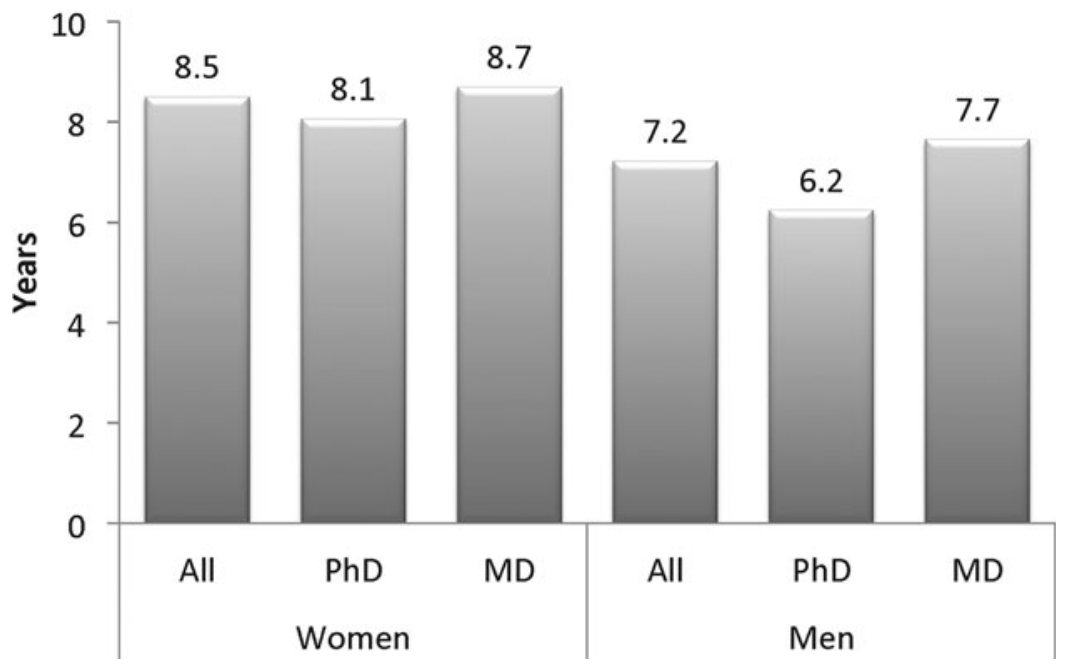

central location and had to be requested from each department; several departments had no updated leadership charts.

\section{Satisfaction}

Sixty-three percent of full-time faculty $(877 / 1392 ; 400$ women, 477 men) responded to the 2013 Satisfaction Survey. More than $50 \%$ of respondents were Associate or Full Professors; the response rate for men and women at each rank was similar to the gender proportion at each rank.

Overall, $21 \%$ (82) of female versus $31 \%$ (148) of male faculty reported being "very satisfied" in their current faculty position, a difference that was statistically significant $(p<0.05$; confidence intervals as shown in Table 3 ). This finding was consistent by gender across ranks from Assistant Professor through Professor. Statistically significant gender differences were also found in the following areas: career progression, transparency of the promotion process, transparency of compensation, and extent to which work-life balance had been a reason to consider leaving the JHUSOM. Twenty-nine percent of women versus $19 \%$ of men considered work-life balance to "a great extent" as a possible reason to leave the JHUSOM; $38 \%$ of women versus $35 \%$ of men considered this aspect to "some extent"; $33 \%$ of women versus $46 \%$ of men responded "not at all." The survey asked whether faculty members had considered any of the following such as "to increase your salary," "to find a more supportive work environment," "for family reasons," "to improve work-life balance," and "unreasonable work expectations" as reasons to leave the JHUSOM; there was no elucidation regarding what faculty considered "work-life balance." How- ever, in the free-text section of the survey, a recurrent theme was the difficult work environment for all faculty especially for mothers/parents. Moreover, $77 \%$ of faculty members who ended their appointments at the JHUSOM in 2013 reported personal/ family/life concerns as the most frequent factor affecting their decision to leave the JHUSOM with no gender differential. Women faculty reported low levels of satisfaction when asked about gender diversity in their departments, with regard to resource allocation, leadership, participation in decision-making, and mentoring.

Surveys in 2009 and 2013 polled faculty as to whether they had experienced or were experiencing sexual harassment at the JHUSOM by asking a single item, "During the past 12 months have you personally experienced sexual harassment in your workplace (unwelcome conduct that is severe or pervasive based on your sex or gender that creates a hostile work environment)?" Approximately 1400 faculty members took the survey each time, and fewer than 20 (1.4\%) answered "yes" each year.

Based on detailed review of quantitative and qualitative data in the aforementioned domains, the CSW made recommendations (Table 4). Based on findings of the CSW, the Dean's office quickly convened a task force that produced a White Paper on promotion; Table 4 includes the task force's recommendations. The key recommendations are that annual reviews should be submitted and tracked beyond the department level; departments with internal promotion committees should offer transparency, although internal committee standards should remain intact; leadership searches should be formal and transparent, drawing from a national diverse pool of candidates; because change occurs with turnover and top-tier

Table 3. Comparisons by Gender of Responses of Full-Time Faculty to Satisfaction Survey

\begin{tabular}{lcr}
\hline & $\begin{array}{c}\text { Female faculty }(\mathrm{n}=400), \\
\mathrm{n}(\%)[95 \% \text { CI] }\end{array}$ & $\begin{array}{r}\text { Male faculty (n=477), } \\
\mathrm{n}(\%)[95 \% \text { CI] }\end{array}$ \\
\hline Very satisfied overall & $82(21 \%)[0.16-0.25]$ & $148(31 \%)[0.27-0.35]$ \\
Very satisfied with career progression & $52(13 \%)[0.095-0.16]$ & $119(25 \%)[0.21-0.29]$ \\
Very satisfied with transparency of promotion & $36(9 \%)[0.06-0.12]$ & $72(15 \%)[0.12-0.18]$ \\
Very dissatisfied with transparency of compensation & $208(52 \%)[0.47-0.57]$ & $191(40 \%)[0.36-0.44]$ \\
Work-life balance will likely influence decision & $116(29 \%)[0.25-0.34]$ & $191(19 \%)[0.15-0.23]$ \\
$\quad$ & &
\end{tabular}

Total $N=877$.

CI, confidence interval; JHUSOM, Johns Hopkins University School of Medicine. 
Table 4. Recommendations of the Committee on the Status of Women

\section{Promotion}

Perform annual reviews of individual faculty within departments

Submit and track annual reviews at the JHUSOM level, not only at department level

Enact systems to track and address lack of academic advancement

When departments utilize internal promotion committees, make promotion criteria transparent and available to faculty, but internal committee standards for promotion should be decided by the individual department

Leadership

Make sponsorship of women explicit by identifying and developing a cadre of qualified women for leadership roles

Promote internal and external executive leadership training; sponsor two female faculty members per year for the American Medical Association Executive Leadership in Academic Medicine and develop a similar internal executive leadership program by the Office of Women in Science and Medicine at the JHUSOM

Continue to provide internal leadership programs for women for increased mentorship and networking opportunities for potential female leaders. These programs also stress conflict resolution and negotiation skills

Establish formal and transparent processes for leadership searches with attention to diversity in both search committees and applicant pools utilizing best practices where available. Consider a diverse national pool of applicants for all leadership positions (e.g., Division Directors, Department Directors, Deans, and Vice Chairs)

Charge departments with creating transparent, dynamic, organizational leadership charts that describe selection processes as well as roles, responsibilities, and compensation tied to leadership positions

Develop succession planning for leadership positions with consideration of promoting gender diversity. Given the limited number of leadership positions and awareness that change occurs primarily with turnover, hold current leaders accountable by having expected performance metrics linked to all top- and mid-tier leadership positions and monitoring performance with annual reviews. Encourage transition when performance goals are not met, despite adequate support. Make attempts to draw from the pool of potential women leaders to fill vacated positions

Expect department leaders to review department/division leadership plans and organizational leadership charts with Vice Dean for Faculty (J.C.). Considering that mid-tier leadership experience must precede top-tier leadership experience, provide opportunities for women to rise to top-level leadership roles through both JHUSOM-wide efforts as well as local departmental/divisional efforts

Increase percentage of women in top leadership (executive and vice dean positions and all Department Directors) to $30 \%$ for the JHUSOM by 2020

Satisfaction

Expect departments and JHUSOM to address work-life issues identified by many women and men as a factor they would consider greatly or to some extent in their decision to leave

Expect departments to make salary/compensation plans, resource allocation, and administrative support transparent

leadership requires mid-tier leadership experience, leadership transition should be encouraged by holding current leaders accountable to performance reviews and timed though renewable contracts; the goal for the proportion of women in top leadership at the JHUSOM will be $30 \%$ by 2020; and departments and JHUSOM should address worklife issues as well as make salary/compensation plans, resource allocation, and administrative support transparent.

We formally presented our recommendations in a report to the Dean, Vice Deans, Department Directors, and the JHUSOM Faculty Senate in November 2014; all faculty received the report electronically.

\section{Discussion}

The aphorism "If you can't measure it, you can't manage it" was true for this Committee's charge. Accrediting, ${ }^{4}$ external funding, ${ }^{8}$ and governing agencies ${ }^{9}$ are moving toward greater reporting of evidence of gender equity. However, these external pressures will only have meaningful impact when individual institutions embrace equity and develop rigorous mechanisms for internal reporting and change. Whereas gender "parity" is used to measure gender balance in a given situation, "equity" means fairness of treatment for women and men, which may include equal treatment or treatment that is different but considered equivalent in terms of rights, benefits, obligations, and opportunities. ${ }^{10}$ At our institution, comprehensive review of quantitative and qualitative data on pro- motion, leadership, and satisfaction revealed opportunities to address gender disparities and led to specific recommendations. Little literature exists on gender benchmarking in academic institutions; therefore, we cannot presume uniform implementation when power and decision-making structures vary among institutions (e.g., centralized vs. decentralized structures). Nonetheless, ongoing data collection and analysis are critical. Improvement in the status of women in academic medicine begins at the level of individual institutions and should incorporate a data-driven process to assess progress and ensure sustainability and accountability.

We focused on academic promotion, leadership, and faculty satisfaction; other institutions may choose to include compensation, which the JHUSOM analyzed before the initiative described herein, resulting in separate recommendations. In as much as faculty satisfaction is interrelated with promotion and leadership, we believe that including it as a metric of gender equity and institutional health is novel. The survey uncovered dissatisfaction with career progression and the transparency of the promotion process for both men and women faculty. These low levels of satisfaction further support the need for change that will benefit all faculty members.

We also found gender disparities in time to promotion. While we do not have data addressing causality, we suspect that women may leave the JHUSOM during Assistant or Associate Professor rank or remain at rank for longer periods of time because of competing personal responsibilities, lack of mentorship/sponsorship, and variability at the department 
review level. Department reviews are not standardized across the JHUSOM. In the Department of Ophthalmology, before meeting his/her Division Chief for the annual review, each faculty member is asked to attribute percentages to academic activities of research, clinic, administration, and teaching; to provide details on each aspect; to list publications from the past year; to list current or planned grant support; to discuss access to mentoring; to describe academic goals for the coming year and to determine whether the faculty member has a path to meet these goals and what the Department or Division needs to provide; and to attach leadership training certificates (if any).

Existing "systems" for tracking faculty promotion data at our institution are inadequate, and improved tools are needed. That women are less likely to be put up for promotion and/or take longer to be promoted has a direct impact on satisfaction as well as on leadership. For example, at our institution, Department Director search committees must be led by Full Professors or Vice Deans, of which there are few women at the JHUSOM. The reason for this requirement is presumably the evidence of leadership ability, not per se the attainment of a certain rank. According to the American Association of Medical Colleges (AAMC), whereas $90 \%$ of teaching hospitals surveyed include women and minorities on search committees for "C-suite" positions [e.g., Chief Medical Officer, Chief Quality Officer (aka Vice President for Quality Management and Improvement), Chief Executive Officer/Executive Director of Faculty Group Practice], only 50\% of hospitals surveyed contact national organizations for women or minority professionals for referrals for such leadership positions, and about $10 \%$ attend meetings of women/minority groups of national professional societies to find candidates. ${ }^{11}$ Inclusion of women on search committees is a start, but having a critical mass of women and/or women occupying important positions on such committees may be more important.

As a result of our work, the selection of leaders at the JHUSOM has become more transparent. With any significant leadership vacancy, a job posting now generally becomes available and a full search ensues. Applicants can be selfnominated, and every search must generate a gender-diverse short list. In addition, in the past 5 years, all leadership positions in the JHUSOM, including Department Directorships, have timed contracts and reviews. This change allows for transition. The Office of Women in Science and Medicine (a by-product of the CSW) has worked diligently to promote women into vacated roles and now has the opportunity to interview candidates for all Department Director searches and to send a summary report to the official search committee.

JHUSOM no longer has a time limit ("tenure clock") at which faculty are permitted to remain at rank, but departmental promotion processes vary widely, from the time at which candidates are presented to departmental committees to stringency of departmental standards to committee deliberations to the decision of the individual Department Director. The gender composition of departmental promotion committees is not known nor publicized. The Director ultimately writes the nomination letter to the JHUSOM promotions committees. The Vice Dean of Faculty selects faculty members for the PPC and the Associate Professor Promotion Committee (APPC); 5-year terms are renewable without a term limit. Currently, $9(30 \%)$ of 30 PPC members and 9 $(50 \%)$ of 18 APPC members are female, indicating gender parity. The steps leading up to presentation to the JHUSOM, however, may result in promotion outcomes that vary across departments. We discovered that male Associate Professors outnumber female Associate Professors presented to the JHUSOM PPC by almost 3 to 1, although this ratio does not reflect the total pool of Associate Professors. Since much of the current promotion process occurs at the level of individual departments, the recommendations to submit and track academic reviews at the SOM level and to examine lack of advancement may result in less variability among departments. We also discovered that data were missing on the number of publications of candidates ( $\mathrm{PhD}, \mathrm{MD}$, men, women) successfully promoted from Associate to Full Professor. With a new online system by which to submit one's promotion files, such data should become available. Although the CSW recommendations are meant to address satisfaction and gender diversity, they may also help retain faculty, regardless of gender, because of improved transparency.

All academic medical centers will benefit from better tools and a national registry on status of faculty by gender. A significant limitation our committee faced was the lack of a centralized repository of data at our institution. Information technology systems to track faculty data within and across institutions would enhance this work. Granular data are valuable for national benchmarking for female faculty. Between 2011 and 2015, the AAMC changed benchmarking of decanal positions from Dean, Senior Associate/Vice Dean, Associate Dean, Assistant Dean stratified by Permanent, Acting, and Interim Deans to Permanent and Interim Dean positions without mention of decanal rank. ${ }^{1,12}$ As the CSW uncovered, nonfaculty women hold a large proportion of (Assistant and Associate) Deanships at the JHUSOM. That the AAMC is no longer tracking discrete data as it once had (e.g., stratification by decanal rank) is all the more reason that individual institutions should assume this responsibility.

An intervention study composed of a before-after trial, with assessment of faculty concerns and perceived change through structured self-administered questionnaires was launched by the Department of Medicine at the JHUSOM between 1990 and 1995. Successful interventions spearheaded by a committed Department Director, other leaders, and a specialist with skills in organizational assessment and change management led to substantive improvements in the development of women's careers in the department in terms of retention and promotion, and "improvements in timeliness of promotions, manifestations of gender bias, access to information needed for faculty development," sense of isolation many women reported, and salary equity. ${ }^{13}$ Men noted improvements in these areas as well. The experience of this department at our own institution demonstrates not only that an institutional strategy can be successful but also that longterm commitment to tracking data and external oversight are necessary to maintain progress.

The CSW lacks power to change policies as that is not its charge. Some may ask whether we should set specific targets for promotion rates, leadership positions held by women (other than the $30 \%$ we recommended for top leadership), and career satisfaction levels. The answer is unclear. The CSW administers the faculty satisfaction survey and reports survey outcomes to the Dean, Vice Deans, and Department Directors every 2 years. Although separate from the current report, the JHUSOM analyzes data for salary and compensation equity 
annually as a result of earlier analyses the CSW did on an annual basis.

It may be premature to see any changes at the JHUSOM level (composed of 31 departments) in the 4 years since we analyzed data, although preliminary analysis by the CSW led to the Office of Women in Science and Medicine becoming involved in Department Director searches and led the Dean to quickly convene the task force on promotion. The number of female Department Directors increased threefold during this period of time. At this time, women comprise $19 \%(6 / 31)$ of Department Directors - two in basic science, three in clinical departments, and one in Art as Applied to Medicine-up from $6 \%(2 / 31)$. It may be more reasonable to examine data on leadership, promotion, and faculty satisfaction for trends over a 10-year period to allow for short-term fluctuations and policy changes occurring within departments and JHUSOM to take effect. Long-term interventions and the commitment of institutional, departmental, and divisional leaders are essential. Although the role of the CSW is advisory, our findings may effect change through emphasis on ongoing data collection and analysis of promotion, faculty satisfaction, and leadership composition. Another tool may be the use of routine exit interviews, which could be encouraged as a means to identify areas of faculty dissatisfaction without fear of reprisals. Such changes will undoubtedly influence the "culture" of the institution. The Code of Medical Ethics Opinion 9.5.5 of the American Medical Association even states, "Inequality of professional status in medicine among individuals based on gender can compromise patient care, undermine trust, and damage the working environment."14

\section{Conclusions}

The standard and systematic data collection and analysis of women's status at our institution have led to recommendations that will form the basis of meaningful and sustainable change on a wider scale. The framework and data we present are important to track both the degree of difficulty with advancement and to gauge whether solutions are effective over time in overcoming barriers. Adjusting for variations in internal structure at different institutions, the possible solutions offered herein could be implemented in most academic settings. It is critical that academic institutions be at the forefront of changes being mandated by external forces. Most important, this work must be performed in a way in which the root causes of inequity can be uncovered and addressed, and progress can be tracked.

\section{Author Disclosure Statement}

No competing financial interests exist.

\section{References}

1. American Association of Medical Colleges. The State of Women in Academic Medicine: The Pipeline and Pathway to Success, 2015-2016. Available at: www.aamc.org/ members/gwims/statistics/gwimsstats2015-2016 Accessed November 24, 2018.

2. Monroe AK, Levine RB, Clark JM, Bickel J, MacDonald SM, Resar LMS. Through a Gender Lens: A View of Gender and Leadership Positions in a Department of Medicine. J Womens Health (Larchmt) 2015;24:837-842.

3. The New York Stem Cell Foundation Initiative on Women in Science and Engineering Institutional Report Card for
Gender Equality. Available at: https://nyscf.org/wp-content/ uploads/2017/06/2017_IWISE-Report-Card-1.pdf Accessed November 24, 2018.

4. In the Nation's Compelling Interest: Ensuring Diversity in the Healthcare Workforce, 2004. Chapter 4: Accreditation and Diversity in Health Professions. Available at: www.nap .edu/read/10885/chapter/6?term=gender\#134 Accessed November 24, 2018.

5. Bucklin BA, Valley M, Welch C, Tran ZV, Lowenstein SR. Predictors of early faculty attrition at one Academic Medical Center. BMC Med Educ 2014;14:27.

6. Ries A, Wingard D, Gamst A, Larsen C, Farrell E, Reznik V. Measuring faculty retention and success in academic medicine. Acad Med 2012;87:1046-1051.

7. Study of Faculty Worklife at the University of WisconsinMadison 2016. Available at: http://wiseli.engr.wisc.edu/ research/w5_facultyversion16.pdf Accessed November 24, 2018.

8. Smith KA, Arlotta P, Watt FM, Solomon SL, Initiative on Women in Science and Engineering Working Group. Seven actionable strategies for advancing women in science, engineering, and medicine. Cell Stem Cell 2015;16:221-224.

9. Butkus R, Serchen J, Moyer DV, Bornstein SS, Hingle ST; Health and Public Policy Committee of the American College of Physicians. Achieving Gender Equity in Physician Compensation and Career Advancement: A Position Paper of the American College of Physicians. Ann Intern Med 2018;168:721-723.

10. $\mathrm{ABC}$ of women workers' rights and gender equality, Second edition, International Labour Office Geneva. Copyright (C) International Labour Organization 2007. Available at: www.ilo.org/wcmsp5/groups/public/_-dgreports/--gender/ documents/publication/wcms_087314.pdf Accessed November 24, 2018.

11. American Association of Medical Colleges. AAMC, 2011: $\mathrm{C}$-suite recruting practices in academic medical centers: How teaching hospitals find top talent. Available at: https:// members.aamc.org/eweb/upload/C-Suite\%20Recruiting\% 20Practices $\% 20$ in $\% 20$ Academic $\% 20$ Medical $\% 20$ Centers $\%$ 20How\%20Teaching\%20Hospitals\%20Find\%20TopTalent .pdf Accessed December 2, 2018.

12. American Association of Medical Colleges. AAMC, 2012: Table 3, Figure 6. Women in academic medicine statistics and medical school benchmarking, 2011-2012. Available at: www.aamc.org/download/305542/data/2012_table 10a .pdf Accessed November 24, 2018.

13. Fried LP, Francomano CA, MacDonald SM, Wagner EM, Stokes EJ, Carbone KM, Bias WB, Newman MM, Stobo JD. Career development for women in academic medicine: Multiple interventions in a department of medicine. JAMA 1996;276:898-905.

14. American Medical Association Code of Medical Ethics. Gender discrimination in medicine 2018. Available at: www.ama-assn.org/delivering-care/gender-discriminationmedicine Accessed November 11, 2018.

Address correspondence to: Irene C. Кио, $M D$ Department of Ophthalmology Wilmer Eye Institute Johns Hopkins University School of Medicine 4924 Campbell Boulevard \#100 Baltimore, MD 21236

E-mail: ickuo@jhmi.edu 